\title{
Trends of caesarean section: an analytical overview of indications
}

\author{
Shruti A. Gavhane, Shilpa N. Chaudhari*
}

Department of Obstetrics and Gynecology, Smt. Kashibai Navle Medical College, Pune, Maharashtra, India

Received: 04 November 2019

Accepted: 28 November 2019

\section{*Correspondence:}

Dr. Shilpa N. Chaudhari,

E-mail: drshilpachaudhari15671@gmail.com

Copyright: (c) the author(s), publisher and licensee Medip Academy. This is an open-access article distributed under the terms of the Creative Commons Attribution Non-Commercial License, which permits unrestricted non-commercial use, distribution, and reproduction in any medium, provided the original work is properly cited.

\section{ABSTRACT}

Background: Caesarean section is one of the commonly performed surgical procedures in obstetrics. An increasing trend has been observed in both primary and repeat caesarean sections. The reasons for its increase are multifaceted. So, this study was carried out to compare the rates of caesarean delivery and to analyse various indications contributing to it.

Methods: This retrospective study was conducted over a period of three year from $1^{\text {st }}$ January 2016 to $31^{\text {st }}$ December 2018 at the department of obstetrics and gynaecology, tertiary care hospital Pune, Maharashtra, India. All caesarean delivery (primary and repeat) taken place during the study period. The rate and indications of caesarean section was calculated over the study period to find out the trends in caesarean delivery. The data so collected was presented with graphical representation. Statistical analysis was performed with SPSS software and t-test was used for continuous data and pearson chi square test for discrete data.

Results: There were a total of 12373 deliveries during the study period out of which, 3701 had delivered via Caesarean Section. So, the rate of caesarean section in the study was found to be $29.91 \%$.

Conclusions: Being a tertiary care hospital, a high rate of caesarean deliveries was observed, Individualization of the indication and careful evaluation, following standardized guidelines, practice of evidenced-based obstetrics and audits in the institution, can help us limit caesarean section rates.

Keywords: Caesarean section, Caesarean rates, Caesarean section rate, Deliveries, Indications of caesarean section, Lower segment caesarean section

\section{INTRODUCTION}

Caesarean section is one of the commonly performed surgical procedure in obstetrics. The rates of caesarean delivery have increased in last few decades in both developed and developing nations. An increasing trend has been observed in both primary and repeat caesarean sections. ${ }^{1}$ The reasons for its increase are multifaceted. According to WHO there is no justification for any region to have caesarean section rates higher than 10$15 \% .^{2}$ In USA, the rate was $27.5 \%$ in the year 2003 which increased to $32.8 \% .^{3}$ In 2015 this increase in caesarean section rate (CSR) has become a major public health issue, because ${ }^{4}$
- It is a burden on health system and imposes strain on families. ${ }^{5}$

- Caesarean deliveries are associated with increased risk of maternal postpartum morbidity, higher chances of new-borns getting respiratory morbidity, less breast feeding causing a possibly more atopic disease. $^{6}$

- There are increased chances of abnormal placentation in future pregnancy with previous caesarean section. ${ }^{6,7}$

More than 85 percent of these operations are performed for four indications-prior caesarean delivery, dystocia, 
foetal jeopardy, abnormal foetal presentation. The latter three compose the main indications for primary caesarean delivery. ${ }^{8}$

In order to understand the degree to which caesarean deliveries may be preventable, it is important to know why caesareans are performed. This study is aimed to find the rate of caesarean deliveries, various indications of the procedure and their relative contribution to the total CSR as well associated maternal morbidity and mortality. This is a step to find out indications of caesarean section which may help us to reduce the incidence rate in the institute in future.

\section{METHODS}

To observe the caesarean delivery rate and various indications contributing, the data was collected in a retrospective manner from all the deliveries that occurred during three-year period between $1^{\text {st }}$ January 2016 to $31^{\text {st }}$ December 2018 in the department of obstetrics and gynecology, in tertiary care hospital Pune (Maharashtra). Data on all live births were collected. In cases of caesarean sections their indications were recorded along with other demographic profile. Whether procedure was done as an emergency or it was a planned surgery. Previous obstetrics history and present obstetric parameters like antenatal care, gestational age, lie and presentation, number of fetuses, birth weight etc. were also recorded in the format and later entered in the Microsoft excel sheet.
The various categories of indications for caesarean sections included-foetal indications, maternal indications and obstetric indications.

Total, primary and repeat caesarean deliveries were calculated. The caesarean rate was calculated as the number of caesarean births in a year divided by total number of deliveries in that year.

The rate for each indication was calculated annually as the number of caesarean births performed for each indication per 1,000 live births.

\section{Statistical analysis}

The data so collected was presented with graphical representation. in tabular form with graphical representation. Statistical analysis was performed with SPSS software and t-test was used for continuous data and Pearson chi square test for discrete data.

\section{RESULTS}

There were total of 12373 deliveries during the study period, out of which rate of vaginal delivery was 8672 $(70.08 \%)$ and rate of caesarean section was 3701 $(29.91 \%)$ as shown in (Table 1$)$.

Out of 3701 caesarean section 1070 (28.91\%) were performed as elective caesarean section and 2631 $(71.08 \%)$ as emergency procedure as shown in (Table 2).

Table 1: Type of deliveries.

\begin{tabular}{|c|c|c|c|c|c|}
\hline & \multicolumn{2}{|l|}{ Vaginal delivery } & \multicolumn{2}{|c|}{ Caesarean section } & \multirow{2}{*}{ Total } \\
\hline & No. of cases (n) & Percentage & No. of cases (n) & Percentage & \\
\hline 2016 & 3287 & $70 \%$ & 1407 & $30 \%$ & 4694 \\
\hline 2017 & 2944 & $69.87 \%$ & 1269 & $30.12 \%$ & 4213 \\
\hline 2018 & 2441 & $70.42 \%$ & 1025 & $29.57 \%$ & 3466 \\
\hline Total & 8672 & $\mathbf{7 0 . 0 8 \%}$ & 3701 & $29.91 \%$ & 12373 \\
\hline
\end{tabular}

Table 2: Distribution of LSCS according to situation.

\begin{tabular}{|c|c|c|c|c|c|}
\hline & \multicolumn{2}{|l|}{ Elective } & \multicolumn{2}{|l|}{ Emergency } & \multirow{2}{*}{ Total } \\
\hline & No. of cases (n) & Percentage & No. of cases (n) & Percentage & \\
\hline 2016 & 421 & $29.92 \%$ & 986 & $70.07 \%$ & 1407 \\
\hline 2017 & 378 & $29.78 \%$ & 891 & $70.21 \%$ & 1269 \\
\hline 2018 & 271 & $26.43 \%$ & 754 & $73.56 \%$ & 1025 \\
\hline Total & 1070 & $28.91 \%$ & 2631 & $71.08 \%$ & 3701 \\
\hline
\end{tabular}

Table 3: Type of caesarean section.

\begin{tabular}{|lll|}
\hline Type of caesarean section & Number of cases(n) & Percentage \\
\hline Primary caesarean section & 2493 & $67.36 \%$ \\
\hline Repeat caesarean section & 1208 & $32.63 \%$ \\
\hline
\end{tabular}


While considering for type of caesarean section patient who underwent primary LSCS were 2493 (67.36\%) and repeat LSCS were 1208 (32.63\%) as shown in (Table 3).

Table 4: Demographic profile.

\begin{tabular}{|lll|}
\hline Age group & No. of cases & Percentage \\
\hline 19-25 years & 1196 & $32.31 \%$ \\
\hline 26-30 years & 1669 & $45.09 \%$ \\
\hline 31-35 years & 712 & $19.23 \%$ \\
\hline$>$ 35 years & 124 & $3.35 \%$ \\
\hline
\end{tabular}

Table 4 represents the demographic profile of the patient which shows that $45.09 \%$ caesarean section were performed in the age group between $26-30$ years counting for maximum no. this was followed by $32.31 \%$ between 19-25 years.
When parity is considered highest number was of primigravida - 1878 (50.74\%), G2 were 1700 cases (45.93\%) and G3 to G5+ were 123 (3.32\%) cases (Figure 1).

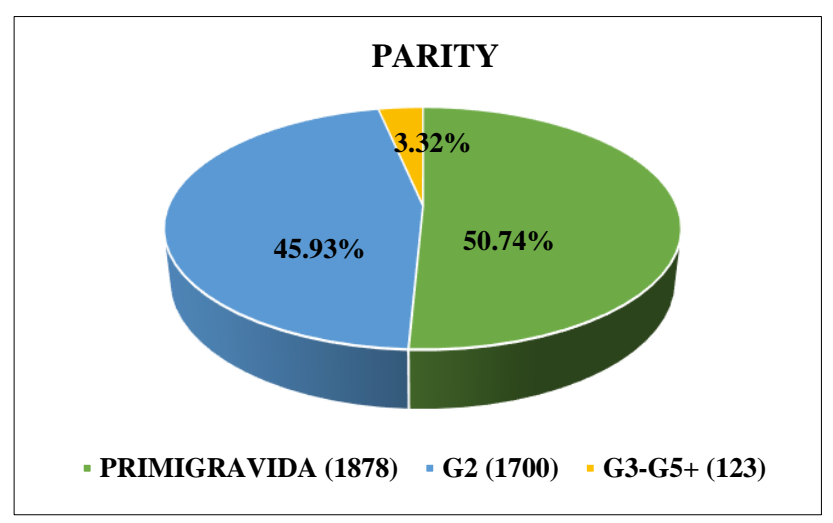

Figure 1: Parity.

Table 5: Distribution of caesarean section.

\begin{tabular}{|lllllllll|}
\hline Indication & $\mathbf{2 0 1 8}$ & & $\mathbf{2 0 1 7}$ & & $\mathbf{2 0 1 8}$ & \multicolumn{3}{c|}{ Total } \\
\hline Previous LSCS & 382 & $27.14 \%$ & 408 & $32.15 \%$ & 418 & $40.78 \%$ & 1208 & $32.63 \%$ \\
\hline Fetal distress & 394 & $28 \%$ & 373 & $29.39 \%$ & 315 & $30.73 \%$ & 1082 & $29.23 \%$ \\
\hline Oligo IUGR & 77 & $5.47 \%$ & 46 & $3.62 \%$ & 32 & $3.12 \%$ & 155 & $4.18 \%$ \\
\hline CPD & 163 & $11.58 \%$ & 111 & $8.74 \%$ & 33 & $3.21 \%$ & 307 & $8.2 \%$ \\
\hline Non progress of labour & 87 & $6.18 \%$ & 92 & $7.24 \%$ & 45 & $4.39 \%$ & 224 & $6.05 \%$ \\
\hline Failure of induction & 198 & $14.07 \%$ & 135 & $10.63 \%$ & 117 & $11.41 \%$ & 450 & $12.15 \%$ \\
\hline Breech & 52 & $3.69 \%$ & 48 & $3.78 \%$ & 29 & $2.8 \%$ & 129 & $3.48 \%$ \\
\hline Transverse lie & 16 & $1.13 \%$ & 14 & $1.10 \%$ & 9 & $0.87 \%$ & 39 & $1 \%$ \\
\hline Unstable lie & 10 & $0.71 \%$ & 8 & $0.63 \%$ & 6 & $0.58 \%$ & 24 & $0.64 \%$ \\
\hline Cord prolapse & 7 & $0.49 \%$ & 7 & $0.55 \%$ & 2 & $0.19 \%$ & 16 & $0.43 \%$ \\
\hline Placenta previa & 8 & $0.56 \%$ & 17 & $1.33 \%$ & 6 & $0.58 \%$ & 31 & $0.8 \%$ \\
\hline Severe abruptio placenta & 13 & $0.92 \%$ & 6 & $0.47 \%$ & 10 & $0.97 \%$ & 29 & $0.78 \%$ \\
\hline Genital warts & - & - & 4 & $0.31 \%$ & - & - & 4 & $0.10 \%$ \\
\hline Cesarean section on demand & - & - & & & 3 & $0.29 \%$ & 3 & $0.081 \%$ \\
\hline
\end{tabular}

Table 6: Indication of repeat caesarean section.

\begin{tabular}{|lllllllll|}
\hline & $\mathbf{2 0 1 6}$ & & $\mathbf{2 0 1 7}$ & & $\mathbf{2 0 1 8}$ & \multicolumn{3}{c|}{ Total } \\
\hline Previous 2 LSCS & 66 & $17.27 \%$ & 41 & $10.04 \%$ & 36 & $8.61 \%$ & 143 & $11.83 \%$ \\
\hline Scar tenderness & 93 & $24.34 \%$ & 75 & $18.38 \%$ & 110 & $26.31 \%$ & 278 & $23.01 \%$ \\
\hline Short inter pregnancy interval & 33 & $8.63 \%$ & 72 & $17.64 \%$ & 61 & $14.59 \%$ & 166 & $13.74 \%$ \\
\hline Not willing for VBAC & 56 & $14.65 \%$ & 69 & $16.91 \%$ & 127 & $30.38 \%$ & 252 & $20.86 \%$ \\
\hline Previous LSCS with fetal distress & 68 & $17.80 \%$ & 92 & $22.54 \%$ & 52 & $12.44 \%$ & 212 & $17.54 \%$ \\
\hline Previous LSCS with CPD & 76 & $19.89 \%$ & 50 & $12.25 \%$ & 31 & $7.41 \%$ & 157 & $12.99 \%$ \\
\hline Total & $\mathbf{3 9 2}$ & & $\mathbf{3 9 9}$ & & $\mathbf{4 1 7}$ & & $\mathbf{1 2 0 8}$ \\
\hline
\end{tabular}

According to our study the most frequent indication for caesarean section was previous LSCS (Lower segment caesarean section) $32.63 \%$, followed by foetal distress $29.23 \%$, add failure of induction $12.15 \%$, a cephalopelvic disproportion $6.4 \%$, non-progress of labour $6.05 \%$ (Table
5). Commonest cause of repeat caesarean section in our study was Scar tenderness $(23.01 \%)$ followed by not willing for VBAC (vaginal birth after caesarean section) $(20.86 \%)$ and foetal distress $(17.54 \%)$ (Table 6). 


\section{DISCUSSION}

Today the excessive use of caesarean section is a serious problem worldwide. In the last decades it has been an increase in the caesarean section practice. The increased number of caesarean section realized is a multifactorial problem, concerning the institutional practices, the physician, social women characteristics and their environment, avoiding difficult manipulative or instrumental vaginal deliveries, foetal distress detected especially with the use of continuous electronic foetal monitoring caesarean section has high rates in condition like Breech presentation, previous caesarean delivery, growth restricted foetus, multiple pregnancy, Improved safety of caesarean section with better surgical techniques, anaesthesia, better availability of blood and its products, advanced antibiotics, and off course fear of labour pains.

\section{Demographic profile}

Analysis of age of the patients showed that $45.09 \%$ of cases were in the age group of maximum fertility i.e. between 26-30 years. Similar results were found in studies conducted by Jawa A et al, Preetkamal et al, Yadav S et al, Saxena N et al and Sarma P et al.

Table 7: Comparative studies.

\begin{tabular}{|llll|}
\hline Study & Place & Study period & CSR \% \\
\hline Present study & Pune, Maharashtra & January 2016-December 2018 & 29.91 \\
\hline Subhashini R et al & Visakhapatnam, Andhra Pradesh & January 2014-December 2014 & 25.66 \\
\hline Yadav RG & Vadodara, Gujarat & January 2013-December 2013 & 28.87 \\
\hline Mittal S et al & Mumbai, Maharashtra & January 2011-December 2011 & 28.93 \\
\hline Jawa A et al & Jaipur, Rajasthan & December 2015-May 2016 & 31.80 \\
\hline Saxena N et al & Dehradun, Uttarakhand & January 2015-December 2015 & 31.40 \\
\hline Sarma P et al & Sonitpur, Assam & January 2015-December 2015 & 27.60 \\
\hline Nikhil A et al & Sola, Gujarat & June 2013-December 2013 & 25.18 \\
\hline Padmaleela K et al & Andhra Pradesh & April 2011-March 2012 & 31.00 \\
\hline Bhasin SK at al & East Delhi, India & September 2003-May 2004 & 34.40 \\
\hline Kambo I et al & 30 medical colleges/teaching hospitals in India & 1998-1999 & 25.40 \\
\hline
\end{tabular}

\section{The caesarean section indications}

In the present study, the most common indication was previous caesarean section $(32.63 \%)$. Similar results were found in studies conducted by Singh G et al, Jiwa A et al, Chavda D et al, Nikhil A et al, Bade P et al and Balci O et al. While not necessarily signaling causation, it is instructive to review events from this era, which may have influenced caesarean rates. In 2001, a similar paper and subsequent editorial describing the risk of uterine rupture in women exposed to vaginal prostaglandins undergoing VBAC suggested that elective repeat caesarean is the safer option when compared with VBAC. ${ }^{9,10}$ Between 1998-2001, new national guidelines recommended that an anaesthesiologist should be available immediately in any hospital where VBAC is offered..$^{11-13}$ In 2003 and 2006, respectively, an ACOG bulletin and NIH consensus statement on elective caesarean per maternal request, suggested more patient autonomy regarding caesarean delivery, reflecting a change in national attitudes. ${ }^{14}$

No trial was given to patients with previous 2 or more sections, those who presented with scar tenderness, dealing with high risk pregnancy, in those previous sections was done for pelvic abnormalities and in those women, who refused for vaginal delivery.

The second common indication in the present study was foetal distress $(29.32 \%)$. The variability of foetal heart tracing interpretation has been documented and a lack of available foetal scalp blood sampling kits has further complicated the objectivity of foetal heart rate interpretation..$^{15,16}$ It is also possible that our effort to standardize foetal heart rate interpretation, as part of our comprehensive patient safety effort, had effects on this observation. ${ }^{17}$ Standardization theoretically attempts to improve the objectivity of this test, however this study is unable to assess exactly what effect standardization had on the rise in this indication for caesarean. Also, this increase is possibly because of decrease in the difficult instrumental deliveries over a period.

Failed induction accounted for- $12.15 \%$; CPD and arrest of labour 8.2\%, nonprogress of labour $6.05 \%$, oligohydramnios/IUGR 4.18\%; Breech-3.48\%; rest in decreasing order were transverse lie, unstable lie, placenta previa, abruptio placenta, caesarean section on demand.

Why providers are more apt to perform caesareans for subjective and elective indications over recent years is a 
complex issue. Medicolegal reasons, scheduling issues, economic pressures, provider- and patient-driven medicalization of birth, increased labour induction rates, and a broader perception of caesareans as safe have all been raised as possibilities. The role of medicolegal concerns has been documented with increasing caesarean rates as malpractice premiums and the number of litigated cases increase. ${ }^{18-20}$ Patient preference also cannot be discounted in these trends. Decision to pursue a caesarean is not one made by the provider alone but one of shared decision making between provider and patient. Patient preferences and perception of risk do contribute, for instance, to decisions to attempt VBAC or vaginal delivery of multiple gestation. This does point out, however, that subjective phenomena may have influence even in seemingly objective criteria. Unfortunately, this analysis cannot account for the contribution of the patient's decision-making to changes in indications for caesarean.

In our study the observed Caesarean section rate was $29.91 \%$ which is almost the double that of given by WHO $10-15 \%$. The caesarean section rate in Africa was $6.2 \%$ whereas in United Kingdom; the CSR was $24.1 \%$ of all live births. ${ }^{21,22}$ Our study had similar results to that of studies as shown in (Table 7).

\section{CONCLUSION}

In order to understand and improve the health care system 's response to increasing trend of caesarean section, consistent information regarding demographic data of women and their preferences to mode of delivery are important to be recorded at different type of health facility.

Vaginal birth is and will always be regarded as the superior mode of delivery compared to caesarean, simply because it has lesser morbidity and mortality involving both the mother and the child. As such, the obstetricians all over the world must encourage vaginal delivery as far as possible. So, focus should be placed on trial of more cases for VBAC and most importantly reducing primary caesarean section rate.

Greatest emphasis attached to foetal welfare in today's small family norm has changed the delivery practices in favour of caesarean section. There is no empirical evidence for an optimum percentage. What matters most is that all women who need caesarean sections receive them (WHO Statement 2010). Safe reduction of the rate of primary caesarean deliveries will require different approaches for each indication. Individualization of the indication and careful evaluation, following standardized guidelines, practice of evidenced-based obstetrics and audits in the institution, can help us limit CSR.

\section{ACKNOWLEDGMENTS}

Authors would like to thank to institutional head, head of department of obstetrics and gynaecology and all our colleagues from department of obstetrics and gynaecology Smt. Kashibai Navle medical college and general hospital for providing help and support for the project.

\section{Funding: No funding sources}

Conflict of interest: None declared

Ethical approval: The study was approved by the Institutional Ethics Committee

\section{REFERENCES}

1. Mittal S, Pardeshi S, Mayadeo N, Mane J. Trends in cesarean delivery: rate and indications. J Obstet Gynecol India. 2014;64(4):251-4.

2. WHO Appropriate technology for birth. Lancet. 1985;2(8452):436-7.

3. Hamilton BE, Martin JA, Ventura SJ. National vital statistics Report ;2011:60:1.

4. Martin JA, Hamilton BE, Osterman MJ, Curtin SC, Mathews T. Births: final data for 2013. 2015. Hyattsville, MD: National Center for Health Statistics. 2019.

5. Gibbons L, Belizán JM, Lauer JA, Betrán AP, Merialdi M, Althabe F. The global numbers and costs of additionally needed and unnecessary caesarean sections performed per year: overuse as a barrier to universal coverage. World Health Report. 2010;30:1-31.

6. Tollanes MC. Increased rate of caesarean sectionscauses and consequences. Tidsskr Nor Laegeforen. 2009;129(13):1329-31.

7. Silver RM, Landon MB, Rouse DJ, Leveo KJ, Spong CY, Thom EA, et al. Risk of placenta previa and accrete to number of previa deliveries. Obstet Gynecol. 2006;107:1226.

8. Barber EL, Lundsberg LS, Belanger K. Indicationa contributing to the increasing cesarean delivery rate. Obstet Gynecol. 2011;118(1):29-38.

9. Greene MF. Vaginal delivery after cesarean sectionis the risk acceptable? N Engl J Med. 2001;345:54-5.

10. Lydon-Rochelle M, Holt VL, Easterling TR, Martin DP. Risk of uterine rupture during labor among women with a prior cesarean delivery. N Engl J Med. 2001;345:3-8.

11. Committee opinion. Induction of labor for vaginal birth after cesarean delivery. Obstet Gynecol. 2002;99:679-80.

12. Approach VBAC deliveries cautiously, experts say. Hosp Peer Rev. 1998;23:189.

13. ACOG practice bulletin. Vaginal birth after previous cesarean delivery. Number 5, July 1999 (replaces practice bulletin number 2, October 1998). Clinical management guidelines for obstetriciangynecologists. American College of Obstetricians and Gynecologists. Int $\mathrm{J}$ Gynaecol Obstet. 1999;66:197-204.

14. ACOG Committee Opinion. Surgery and patient choice: the ethics of decision making. Obstet Gynecol. 2003;102:1101-6. 
15. Beaulieu Beaulieu MD, Fabia J, Leduc B, Brisson J, Bastide A, Blouin D, Gauthier RJ, Lalonde A. The reproducibility of intrapartum cardiotocogram assessments. Can Med Associ J. 1982;127(3):214.

16. Nielsen PV, Stigsby B, Nickelsen C, Nim J. Intraand inter-observer variability in the assessment of intrapartum cardiotocograms. Acta Obstet Gynecol Scand. 1987;66:421-4.

17. Pettker CMTSNE, Buhimschi CS, Raab CA, Copel JA, Kuczynski E, Lockwood CJ, et al. Impact of a comprehensive patient safety strategy on obstetric adverse events. Am J Obstet Gynecol. 2009;200(5):492.e1-8.

18. Murthy K, Grobman WA, Lee TA, Holl JL. Association between rising professional liability insurance premiums and primary cesarean delivery rates. Obstet Gynecol. 2007;110:1264-9.

19. Ryan K, Schnatz P, Greene J, Curry S. Change in cesarean section rate as a reflection of the present malpractice crisis. Conn Med. 2005;69:139-41.
20. Zwecker P, Azoulay L, Abenhaim HA. Effect of fear of litigation on obstetric care: a nationwide analysis on obstetric practice. Am J Perinatol. 2011;28(4):277-84.

21. Chu K, Cortier H, Maldonado F, Mashant T, Ford N, Trelles M. Cesarean section rates and indications in sub-Saharan Africa: a multi-country study from Medecins sans Frontieres. PloS One. 2012;7(9):e44484.

22. WHO Euro Health for all database, 2014. Available at: http://data.euro.who.int/hfadb/(53).

Cite this article as: Gavhane SA, Chaudhari SN. Trends of caesarean section: an analytical overview of indications. Int J Reprod Contracept Obstet Gynecol 2020;9:288-93. 